\title{
EXPANSÃO, INTERIORIZAÇÃO E ACESSO AO ENSINO SUPERIOR NO ESTADO DA BAHIA
}

\author{
Luciana Alaíde Alves Santana ${ }^{1}$ \\ Universidade Federal do Recôncavo da Bahia \\ http://orcid.org/0000-0002-1103-1158 \\ Everson Meireles ${ }^{2}$ \\ Universidade Federal do Recôncavo da Bahia \\ http://orcid.org/0000-0002-1715-006X \\ Paulo Gabriel Soledade Nacif ${ }^{3}$ \\ Universidade Federal do Recôncavo da Bahia \\ http://orcid.org/0000-0002-4781-3055
}

\section{RESUMO:}

Este artigo tem a finalidade de apresentar a evolução do acesso ao ensino superior (ES) no estado da Bahia e em seus Territórios de Identidade (TI) e municípios, bem como relacionar este processo com o perfil da rede de instituições de ensino superior (IES) no estado. Utilizou-se de dados secundários do Censo Demográfico dos anos 2000 e 2010 e projeção para 2020. Foram utilizados, também, dados públicos disponíveis no Cadastro Nacional de Cursos e Instituições de Educação Superior (Cadastro e-MEC) e consulta aos sítios de IES, para caracterizar as instituições com sede na Bahia. No período estudado, o acesso ao ES cresceu no estado, este foi maior nos TI mais desenvolvidos. Registrou-se o crescimento da presença de pessoas autodeclaradas negras e de baixa renda no ES, mas esta ampliação não foi suficiente para atingir os níveis de representatividade destes grupos na sociedade baiana. As IES do estado caracterizam-se em maioria por faculdades com fins lucrativos e o acesso ao ES esteve diretamente ligado a maior disponibilidade de instituições no território. Considera-se importante a regulação do Estado no processo de implantação de novas IES, não só pensando na localização destas, mas também, nos cursos ofertados e sua relação com o contexto territorial, em políticas que promovam acesso dos grupos excluídos (regiões menos desenvolvidas, grupos étnico-raciais e população de baixa renda), nos currículos que considerem a sociedade multirracial, multiétnica e diversa em povos, comunidades e segmentos variados de classe.

Palavras-chave: Ensino superior, Inclusão. Interiorização, Territórios de identidade.

\section{ABSTRACT: \\ EXPANSION, INTERIORIZATION AND ACCESS TO HIGHER EDUCATION IN THE STATE OF BAHIA}

This article aims to present the evolution of access to higher education (ES) in the state of Bahia and in its Identity Territories (IT) and municipalities, as well as to relate this process to the profile of the network of higher education institutions (HEI) in the state. Secondary data from the Demographic Census of the years 2000 and 2010 and projection for 2020 were used. Public data available in the National Reg-

\footnotetext{
1 Doutora em Educação. Professora (UFRB). Observatório da Inclusão e Diversidade na Educação Brasileira (DIVERSIFICA). E-mail: lualaide@ufrb.edu.br

2 Doutor em Psicologia. Professor (UFRB). Observatório da Inclusão e Diversidade na Educação Brasileira (DIVERSIFICA). E-mail: emeireles@ufrb.edu.br

3 Doutor em Agronomia.Professor Titular (UFRB). Observatório da Inclusão e Diversidade na Educação Brasileira (DIVERSIFICA).E-mail: paulogabrielnacif@gmail.com
} 
ister of Courses and Institutions of Higher Education (Cadastro e-MEC) and consultation of IES sites were also used. to characterize institutions based in Bahia. During the period studied, access to ES grew in the state, which was higher in more developed IT. There was a growth in the presence of self-declared black and low-income people in ES, but this expansion was not enough to reach the levels of representativeness of these groups in Bahian society. The state HEIs are mostly characterized by for-profit colleges and access to higher education was directly linked to greater availability of institutions in the territory. State regulation is considered important in the process of implementing new HEIs, not only thinking about their location, but also about the courses offered and their relationship with the territorial context, in policies that promote access for excluded groups (less developed regions, ethnic-racial groups and low-income population), in curricula that consider multiracial, multi-ethnic and diverse society in different peoples, communities and segments of class.

Keywords: Higher Education, Inclusion. Interiorization, Identity Territories.

\section{RESUMEN:}

\section{EXPANSIÓN, INTERIORIZACIÓN Y ACCESO A LA EDUCACIÓN SUPERIOR EN EL ESTADO DE BAHÍA}

Este artículo tiene como objetivo presentar la evolución del acceso a la educación superior (ES) en el estado de Bahía y en sus Territorios de Identidad (TI) y municipios, así como relacionar este proceso con el perfil de la red de instituciones de educación superior (IES) en el estado. Se utilizaron datos secundarios del Censo Demográfico de los años 2000 y 2010 y proyección para 2020. También se utilizaron los datos públicos disponibles en el Registro Nacional de Cursos e Instituciones de Educación Superior (Cadastro e-MEC) y la consulta de los sitios de IES, caracterizar las instituciones radicadas en Bahía. Durante el período estudiado, el acceso a ES creció en el estado, siendo mayor en TI más desarrolladas. Hubo un crecimiento en la presencia de personas autodeclaradas negras y de bajos ingresos en ES, pero esta expansión no fue suficiente para alcanzar los niveles de representatividad de estos grupos en la sociedad bahiana. Las IES estatales se caracterizan principalmente por universidad con fines de lucro y el acceso a la educación superior estaba directamente vinculado a una mayor disponibilidad de instituciones en el territorio. La regulación estatal se considera importante en el proceso de implementación de nuevas IES, no solo pensando en su ubicación, sino también en los cursos que se ofrecen y su relación con el contexto territorial, en políticas que promuevan el acceso de grupos excluidos (regiones menos desarrolladas, etnias-raciales, grupos y población de bajos ingresos), en currículos que consideren la sociedad multirracial, multiétnica y diversa en diferentes pueblos, comunidades y segmentos de clase.

Palabras clave: Educación superior, Inclusión. Interiorización, Territorios de Identidad.

\section{Introdução}

Um marco histórico que determinou o início do ensino superior no Brasil foi a criação, em 1808 pelo príncipe regente D. João, de uma escola de Cirurgia no Hospital Militar de Salvador da Bahia. A partir deste momento, o regime político republicano enfatizou um modelo de educação superior que se estruturou a partir de faculdades isoladas e com oferta de cursos de alto prestígio social (ALMEIDA FILHO, 2016). No início do século XX, algumas iniciativas regionais de implantação de universidades foram registradas nos estados do Amazonas (1909) e do Paraná (1912), contudo tiveram uma existência breve e logo foram extintas (MORHY, 2004). O processo de criação de universidade no país se deu a partir da década de 30 do século XX. 
Nestes moldes, o ensino superior no país caracterizou-se como um nível educacional acessível para poucos, especialmente, grupos populacionais de maior renda. Registra-se que o processo de expansão deste subsetor intensificou-se, somente, a partir da década de 1990, com uma ação impulsionadora do governo federal, por meio do Decreto 2306/97 (BRASIL, 1997). Este documento foi um marco que definiu o atual arranjo do ensino superior no Brasil, com forte influência do governo neoliberal vigente na época, que visava estimular a abertura para o crescimento do capital privado na oferta da educação superior, isso resultou na mercantilização do setor (BRITO, 2014; BERTOLIN, 2009; CORBUCC, 2004, CUNHA, 2003). Em 1995, existiam registros de 894 instituições de ensino superior, este número passou para 1.157 em 2000, sendo $13,3 \%$ públicas e $86,7 \%$ privadas (INEP, 2004).

Um novo ciclo de expansão do ensino superior no Brasil iniciou-se em 2004, no qual, apesar do estímulo à expansão da rede federal pública de ensino superior por meio do Programa de Apoio a Planos de Restruturação e Expansão das Universidades Federais - REUNI (BRASIL, 2007), destaca-se, também, uma ação governamental de fomento ao desenvolvimento do setor privado (AGUIAR, 2016). Como resultado destes sucessivos estímulos de diferentes governos, em 2004 a rede de IES praticamente dobrou $(n=2.013)$ e manteve a curva crescente atingindo um número de 2.378, em 2010 (INEP, 2012). No último censo da educação superior publicado do pelo INEP, houve registro de 2.537 instituições, sendo 2.238 (88,2\%) privadas e 299 (11,8\%) públicas (INEP, 2019). Deste modo, uma característica marcante do subsistema de ensino superior brasileiro é a presença marcante de instituições privadas, não universitárias.

Os estudos a seguir trazem informações sobre o acesso de populações historicamente excluídas deste nível de ensino. Oliveira e Silva (2017) realizaram um estudo que os resultados apontaram para maior inserção de alunos negros e de classes sociais menos favorecidas, após a criação dos programas de inclusão social no Ensino Superior. Os autores chamaram atenção para as características do novo perfil social das IES, este possui diferenças importantes, visto que foi observado uma maior concentração de negros (pretos e pardos) e pessoas de baixa renda nas áreas de Ciências Humanas e Linguística, Letras e Artes.

Terra et, al (2019) analisaram a evolução da legislação relacionada as políticas afirmativas de acesso ao ensino superior no Brasil, com o intuído de verificar a evolução da presença de pessoas autodeclaradas negras (pretas e pardas) no ensino superior brasileiro. Este autor concluiu que a legislação permitiu avanços, todavia ainda existe a necessidade de maior evolução no sentido de ampliar a diversidade na universidade brasileira. Santana, Meireles e Carvalho (2019) identificaram que até o ano de 2016, 38,2\% das matrículas em vagas novas nas IFES brasileiras eram de ingressantes beneficiários de programas de reserva de vagas. 
Lopes, Silva e Ferreira (2021) desenvolveram um estudo com a finalidade de medir o alcance da Lei de Cotas na Universidade Federal de Alfenas-MG. Os resultados apontaram para importância da ação afirmativa para promover o acesso de estudantes negros (pretos e pardos) e indígenas. Todavia, também, identificaram uma subocupação de vagas por parte deste grupo. Os autores assinalaram para a necessidade do desenvolvimento de ações institucionais que possam ampliar o alcance do processo seletivo das instituições, para um maior contingente de estudantes egressos de ensino médio de escolas públicas, com o perfil étnico-racial previsto na referida Lei. Em outro estudo de abrangência nacional, Santana, Meireles, Carvalho e Nacif (2021) também identificaram que, embora a Lei de cotas tenha permitido maior acesso a estudantes negros e de baixa de renda às IFES, grande parcela dos beneficiários da referida Lei eram brancos/as e de maior renda familiar per capita.

Neste contexto recente de ampliação do acesso ao ensino superior no Brasil, ainda, observou-se um processo de interiorização do campus universitário brasileiro. Oliveira (2019) apontou que a desconcentração geográfica do ensino superior no Rio Grande do Sul intensificou-se a partir de 1991. O autor destacou que a expansão das IES no estado, no período entre 1991 e 2013, foi estimulada pela ampliação do número de instituições privadas. Neste mesmo período, o autor também destacou o crescimento da rede federal de ensino superior com abertura de quatro campi da Universidade Federal do Rio Grande do Sul, quatro novas universidades federais e três Institutos Federais. Andriola e Suliano (2015) analisaram os impactos sociais da criação de campus da Universidade Federal do Ceará, em cidades do interior do estado no âmbito do plano REUNI.

Rodriguez e Martins (2005) analisaram a expansão do ensino superior no estado do Mato Grasso do Sul. As autoras constataram que a ampliação da oferta do ensino superior ocorreu em dois períodos, um na década de 1960, que foi promovido pela implantação de uma universidade federal e seus campi e, posteriormente, na década de 1990. Este segundo momento foi caracterizado pela mercantilização da educação superior, interiorização do ensino superior por meio da implantação de faculdades que ofertavam cursos de baixo custo e no turno noturno.

Teixeira e Larrea-Killinger (2015) analisaram a implantação da Universidade Federal do Sul da Bahia (UFSB), com a finalidade de caracterizar o perfil dos jovens estudantes frente à chegada de uma instituição pública na região. Boaventura et al (2015) relatou o processo de expansão do ensino superior na Bahia por meio da implantação das universidades estaduais. Santos (2017) discutiu o processo de expansão e interiorização do ensino superior na Bahia, 
a partir da interiorização da UFBA, com o Campus Reitor Edgar Santos - em Barreiras - e a posterior criação da Universidade Federal do Oeste da Bahia (UFOB).

Mota Junior e Torres (2017) analisaram o contexto histórico da educação superior no Estado da Bahia. Os autores destacaram a presença de uma única instituição pública atuando no território baiano - Universidade Federal da Bahia - por mais de meio século localizada no capital do estado. Adicionalmente, caracterizaram a interiorização promovida pela implantação de universidades estaduais: Universidade Estadual de Feira de Santana - UEFS em 1970; a Universidade Estadual do Sudoeste baiano - UESB em 1980; a Universidade do Estado da Bahia - UNEB em 1983 e a Universidade Estadual de Santa Cruz - UESC em 1991, bem como a forte expansão do setor privado a partir da década de 1990.

Diante deste cenário caracterizado pela expansão, interiorização, diversificação do campus universitário no país e mercantilização do ensino superior, este estudo tem a finalidade de apresentar evolução do acesso ao ensino superior no estado da Bahia e em seus Territórios de Identidade (TI). Concomitantemente, pretende-se relacionar este processo com o perfil da rede de instituições de ensino superior no estado. Entende-se que essa abordagem pode ser relevante para agentes públicos que se ocupam de questões relacionadas com a reestruturação territorial, ampliação do tecido urbano e políticas públicas. Especialmente, no estado da Bahia, onde o governo do estado passou a reconhecer a existência de 27 Territórios de Identidade com o objetivo de identificar prioridades temáticas definidas a partir da realidade local, possibilitando o desenvolvimento equilibrado e sustentável entre as regiões (BAHIA, 2007).

\section{Método}

Trata-se de um estudo que se utilizou de dados secundários, obtidos a partir dos microdados públicos do Censo Demográfico realizado pelo Instituto Brasileiro de Geografia e Estatísticas (IBGE), especificamente das edições dos anos 2000 e 2010. Em razão de não ter sido realizado o Censo no ano de 2020, utilizou-se um procedimento estatístico que utiliza fórmula de previsão de dados a partir da distribuição dos dados censitários de 2000 e 2010, para projetar o acesso ao ES no ano de 2020. Esta fórmula de previsão é padrão e está disponível no pacote Office Excel 2010, assim foi possível obter estimativas de projeção dos dados de interesse para o referido ano (i.e. 2020).

Os dados de acesso projetados para 2020, neste estudo, apontaram para evoluções favoráveis, uma vez que foram produzidos considerando o comportamento destas variáveis nas décadas anteriores e, estes períodos, apontaram para avanços na ampliação do acesso e conclusão do 
Ensino Superior no país. Contudo, destaca-se que estas inferências estatísticas não dão conta de apreender as mudanças de cenário entre as décadas, dito isso, para ressaltar que a última década (2011-2020) foi diferenciada em relação a aspectos econômicos, sociais, investimento público com educação e sanitários em relação às anteriores.

O objeto de análise foi o acesso da população brasileira com 18 anos ou mais ao ensino superior no período supracitado, considerando as seguintes variáveis socioeconômicas e demográficas: localização (urbana ou rural); faixa etária; raça/cor e renda mensal familiar per capita. Para estas variáveis foram extraídos dados de acesso (frequências e percentuais) considerando o Brasil, a região Nordeste e o Estado da Bahia como um todo. Posteriormente foram analisados os dados de acesso da população com 18 anos ou mais ao Ensino Superior e criados os percentuais de acesso para cada um dos 27 Territórios de Identidade do Estado da Bahia.

Para caracterizar o perfil da rede de Instituições de Ensino Superior no Estado da Bahia foram utilizados dados públicos disponíveis no Cadastro Nacional de Cursos e Instituições de Educação Superior (Cadastro e-MEC), a partir do qual foram extraídas as seguintes informações daquelas IES com status ativo no Cadastro: organização acadêmica; categoria administrativa; ano de criação da IES; tipo de credenciamento (e.g. presencial ou à distância); Índice Geral de Cursos da IES (IGC) e município de localização da IES. A partir desta última variável (município) as IES foram classificadas como localizadas na capital ou no interior, bem como categorizadas nos seus respectivos Territórios de Identidade do Estado da Bahia. Informações adicionais sobre os campi das IES foram coletadas nos sites das instituições.

As informações do Censo Demográfico (2000, 2010 e projeções para 2020), foram exportadas para o software estatístico IBM SPSS Statistics 23, para transformar em informações sobre o fenômeno estudado, por meio de recursos da estatística descritiva.

\section{Resultados}

\section{Acesso ao ensino superior na Bahia e em seus territórios de identidade}

A Figura 01 apresenta a evolução do percentual da população com 18 anos ou mais que acessou o ensino superior, considerando o país, a região nordeste e o estado da Bahia. 
Figura 1. Evolução do percentual da população do Brasil, da região Nordeste e do estado da Bahia, com 18 anos ou mais, que acessou o ensino superior por zona de localização, 2000, 2010 e projeção 2020.

\begin{tabular}{|l|c|c|c|c|c|c|c|c|c|c|}
\hline & BR & NE & BA & BR & NE & BA & BR & NE & BA \\
\hline Urbano & 11,2 & 7,1 & 5,9 & 18,2 & 13,4 & 12,7 & 25,2 & 19,8 & 19,6 \\
\hline Rural & 1,1 & 0,5 & 0,3 & 3,0 & 2,1 & 1,5 & 5,0 & 3,7 & 2,7 \\
\hline Total & 9,5 & 5,2 & 4,2 & 16,0 & 10,6 & 9,8 & 22,6 & 15,9 & 15,3 \\
\hline
\end{tabular}

Fonte: Censo Demográfico IBGE 2000, 2010 e projeção para 2020, minerados pelo Observatório da Inclusão e Diversidade na Educação - DIVERSIFICA/UFRB.

A partir da Figura 01 observa-se que nos anos 2000 o percentual de acesso ao ensino superior (ES), para a população residente no estado da Bahia $(4,2 \%)$ encontrava-se abaixo do registrado para a população Brasileira (9,5\%) e Nordestina (5,2\%). Na edição seguinte do Censo Demográfico, em 2010, este percentual para a Bahia subiu para 9,8\%, se aproximando mais do observado para a região Nordeste (10,6\%), embora ainda distante do percentual observado para o Brasil como um todo (16,0\%). A projeção realizada no presente estudo, para o ano de 2020, apontou para a manutenção da tendência de crescimento de acesso ao ES para a população com idade igual ou superior a dezoito anos: Brasil (22,6\%); Nordeste (15,9\%) e Bahia (15,3\%). Verifica-se, ainda, que em todos os níveis territoriais analisados ocorreu uma ampliação do acesso ao ES para as pessoas residentes em zona rural com idade igual ou superior a dezoito anos. Todavia, a grande maioria das pessoas com acesso a este nível de ensino concentrava-se em zonas urbanas.

A faixa de idade considerada adequada para acesso ao ES é entre 18 a 24 anos (Brasil, 1996). Neste grupo etário da população brasileira, nordestina e baiana verificou-se uma expressiva ampliação no percentual de acesso entre os anos 2000 e 2010, bem com na projeção para o ano de 2020. As faixas etárias com maior acesso ao ES foram 25 a 29 anos e 30 a 39 anos (Tabela 01). 
Tabela 1. Evolução do percentual da população do Brasil, da região Nordeste e do estado da Bahia que acessou o ensino superior por faixa etária, 2000, 2010 e projeção 2020.

\begin{tabular}{|c|c|c|c|c|c|c|c|c|c|}
\hline \multirow{3}{*}{$\begin{array}{l}\text { Faixas } \\
\text { etárias }\end{array}$} & \multicolumn{9}{|c|}{$\begin{array}{l}\text { \% da população acima de } 18 \text { anos com acesso ao ensino superior } \\
\text { em diferentes edições do Censo Demográfico }\end{array}$} \\
\hline & \multicolumn{3}{|c|}{2000} & \multicolumn{3}{|c|}{2010} & \multicolumn{3}{|c|}{ Projeção 2020} \\
\hline & $\mathrm{BR}$ & $\mathrm{NE}$ & BA & $\mathrm{BR}$ & $\mathrm{NE}$ & BA & $\mathrm{BR}$ & $\mathrm{NE}$ & $\mathrm{BA}$ \\
\hline 18 a 24 & 9,1 & 4,4 & 3,7 & 18,7 & 12,0 & 10,3 & 28,3 & 19,5 & 16,9 \\
\hline 25 a 29 & 10,6 & 5,7 & 4,8 & 21,8 & 14,0 & 13,4 & 32,9 & 22,3 & 22,0 \\
\hline 30 a 39 & 11,0 & 6,3 & 4,9 & 18,3 & 12,1 & 12,1 & 25,5 & 18,0 & 19,3 \\
\hline 40 a 59 & 10,4 & 6,3 & 5,0 & 14,6 & 9,9 & 8,8 & 18,8 & 13,5 & 12,7 \\
\hline$\geq 60$ & 4,1 & 2,0 & 1,8 & 7,8 & 4,7 & 4,2 & 11,6 & 7,3 & 6,5 \\
\hline Total & 9,5 & 5,2 & 4,2 & 16,0 & 10,6 & 9,8 & 22,6 & 15,9 & 15,3 \\
\hline
\end{tabular}

Fonte: Censo Demográfico IBGE 2000, 2010 e projeção para 2020 minerados pelo Observatório da Inclusão e Diversidade na Educação - DIVERSIFICA/UFRB.

Quando o acesso ao ensino superior foi analisado a partir da autodeclaração de raça/cor, verificou-se que a população que se autodeclarou branca tinha uma vantagem nos anos 2000, em relação ao grupo populacional autodeclarado preto, pardo e indígena (Figura 02). Contudo, apesar do aumento, expressivo, do acesso ao ES para os grupos populacionais estruturalmente excluídos deste nível de ensino, entre os anos de 2000 a 2010, não foi suficiente para reduzir a desigualdade no acesso entre estes grupos e o grupo populacional autodeclarado branco. Estes resultados corroboram com resultados obtidos por Oliveira e Silva (2017), Terra (2019), e Lopes, Silva e Ferreira (2021).

Figura 2. Evolução do percentual da população do Brasil, da região Nordeste e do estado da Bahia, com 18 anos ou mais, que acessou o ensino superior por raça/cor, 2000, 2010 e projeção 2020.

\begin{tabular}{|c|c|c|c|c|c|c|c|c|c|}
\hline & BR & $\mathrm{NE}$ & BA & BR & $\mathrm{NE}$ & BA & BR & $\mathrm{NE}$ & BA \\
\hline & \multicolumn{3}{|c|}{2000} & \multicolumn{3}{|c|}{2010} & \multicolumn{3}{|c|}{ Projeção 2020} \\
\hline Branco/a & 13,8 & 9,6 & 8,9 & 22,8 & 17,0 & 16,5 & 31,8 & 24,5 & 2,4 \\
\hline Preto/a & 3,3 & 2,0 & 2,1 & 8,6 & 7,1 & 7,2 & 14,0 & 12,1 & 12,3 \\
\hline Amarelo/a & 34,3 & 11,4 & 10,5 & 24,3 & 11,6 & 11,4 & 14,3 & 11,8 & 12,3 \\
\hline Pardo/a & 3,7 & 3,1 & 2,6 & 9,3 & 8,0 & 8,0 & 14,8 & 12,8 & 13,4 \\
\hline Indígena & 3,4 & 3,5 & 3,7 & 6,7 & 7,1 & 6,9 & 10,1 & 10,8 & 10,0 \\
\hline Iño declarado & 6,4 & 3,7 & 2,5 & 0,4 & 0,6 & 0,0 & & & \\
\hline
\end{tabular}

Fonte: Censo Demográfico IBGE 2000, 2010 e projeção para 2020 minerados pelo Observatório da Inclusão e Diversidade na Educação - DIVERSIFICA/UFRB. 
Na Figura 03 verifica-se a grande discrepância de acesso ao ES da população em função da renda. Percebeu-se que ocorreu uma redução do acesso para população de maior renda, entre os anos 2000-2010, isso se deu em função da melhoria da condição econômica da população, contudo este ganho não foi acompanhado de melhorias sociais, como por exemplo: maior acesso a escolarização. Quanto ao grupo de menor renda (até 1,5 salários mínimos) ocorreu ampliação no acesso. Na Bahia, apesar da ampliação do acesso para este grupo populacional está aquém do registrado para o Brasil e Nordeste, notou-se um incremento de $200 \%$ entre 2000 e 2010. A projeção realizada, neste estudo, para o ano de 2020 manteve a tendência de incremento $(215 \%)$, em relação ao censo demográfico de 2010.

Figura 3. Evolução do percentual da população do Brasil, da região Nordeste e do estado da Bahia, com 18 anos ou mais, que acessou o ensino superior por familiar renda, 2000, 2010 e projeção 2020.

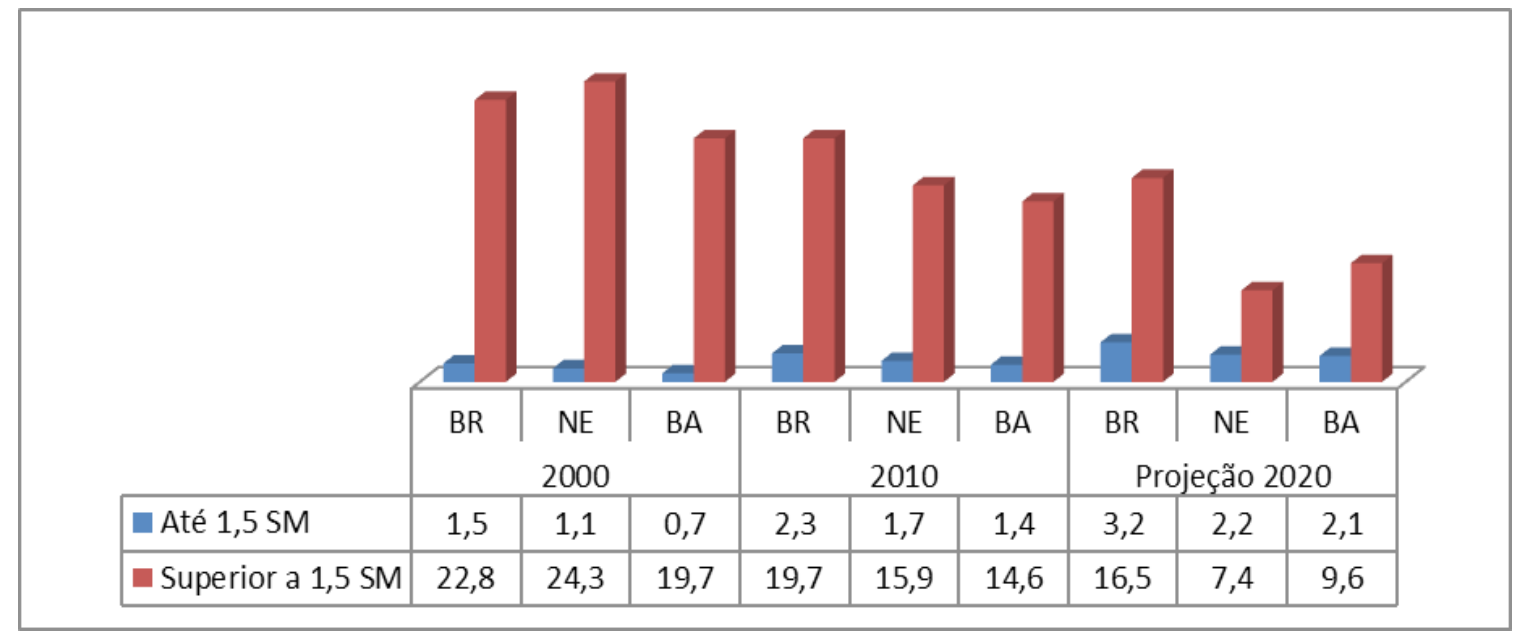

Fonte: Censo Demográfico IBGE 2000, 2010 e projeção para 2020 minerados pelo Observatório da Inclusão e Diversidade na Educação - DIVERSIFICA/UFRB.

A análise do acesso ao ensino superior no estado da Bahia estratificada por territórios de identidade -TI (Tabela 02) permitiu observar que houve crescimento no acesso em todos os TI do estado. No TI Região Metropolitana de Salvador (RMS), em todos os anos analisados, verificou-se maior acesso da população ao ES superior que o registado nos demais territórios (2000: 10,44\%; 2010: 18,19\% e Projeção 2020: 25,95\%). O TI que ocupou a segunda colocação em relação ao acesso da população ao ES foi o Litoral Sul (2000: 3,89\%; 2010: 10,07\%; Projeção 2020: 16,25\%). Estes resultados confirmam a tendência histórica de concentração do ensino superior baiano na capital e em sua região metropolitana assinalada, anteriormente, por meio do estudo de Mota Junior e Torres (2017). 
Em alguns territórios o crescimento do acesso da população ao ES no período entre 2000 a 2010 foi bastante expressivo, em outros a ampliação foi menos acentuada. Os territórios de identidade do estado da Bahia com maior crescimento no acesso ao ES foram: Vale do Jiquiriçá, Sisal, Bacia do Jacuípe, Baixo Sul, Irecê, Chapada Diamantina, Velho Chico, Bacia do Rio Corrente, Semiárido Nordeste II, Bacia do Paramirim (Figura 04). Destaca-se que os TI do estado com maior incremento no acesso ao ES foram aqueles que apresentavam os menores percentuais de acesso no ano 2000. Todos, exceto Baixo Sul, possuíam percentual de acesso ao ES, naquele ano, inferior a $1 \%$ da população. Apesar do aumento expressivo no acesso ao ES, nestes TI, no ano de 2010 e na projeção para 2020, os mesmos, ainda, ostentavam os menores percentuais de acesso ao ES entre os territórios (Tabela 02).

Os quatro territórios de identidade do estado da Bahia com menor incremento no percentual de acesso ao ES foram: Região Metropolitana de Salvador, Sertão do São Francisco, Portal do Sertão e Litoral Sul (Figura 04). Estes representam espações geográficos do estado com maior desenvolvimento econômico, bem como concentram a capital do estado e cidades de grande porte como: Feira de Santana, Juazeiro, Itabuna e Ilhéus. Desde o ano de 2000, o acesso à formação de nível superior, nestes territórios, era superior aos demais, com os seguintes percentuais: $10,44 \%, 2,92 \%, 3,86 \%, 3,89 \%$ respectivamente (Tabela 02 ).

Tabela 2. Evolução do percentual da população por território do estado da Bahia, com 18 anos ou mais, que aces sou o ensino superior, 2000, 2010 e projeção 2020.

\begin{tabular}{|l|c|c|c|}
\hline \multirow{2}{*}{ Territórios de Identidade (TI) } & \multicolumn{3}{|c|}{$\%$ da população acima de 18 anos com acesso } \\
& \multicolumn{3}{|c|}{ ao ensino superior em diferentes edições do Censo Demo- } \\
& 2000 & 2010 & Prófico \\
\cline { 2 - 4 } & 10,44 & 18,19 & 25,95 \\
Região Metropolitana de Salvador & 3,89 & 10,07 & 16,25 \\
Litoral Sul & 3,52 & 9,48 & 15,43 \\
\hline Itaparica & 2,84 & 9,03 & 15,22 \\
\hline Bacia do Rio Grande & 3,86 & 9,52 & 15,19 \\
\hline Portal do Sertão & 2,20 & 8,49 & 14,79 \\
\hline Extremo Sul & 2,77 & 8,69 & 14,62 \\
\hline Costa do Descobrimento & 1,94 & 7,85 & 13,76 \\
\hline Sudoeste baiano & 2,22 & 7,55 & 12,87 \\
\hline Médio Rio de Contas & 1,91 & 7,01 & 12,12 \\
\hline Recôncavo & 1,16 & 5,77 & 10,39 \\
\hline Baixo Sul & 2,92 & 6,61 & 10,31 \\
\hline Sertão do São Francisco & & & \\
\hline
\end{tabular}




\begin{tabular}{|l|c|c|c|}
\hline Sertão Produtivo & 1,87 & 6,04 & 10,22 \\
\hline Piemonte Norte do Itapicuru & 1,69 & 5,89 & 10,10 \\
\hline Litoral Norte e Agreste Baiano & 1,70 & 5,72 & 9,73 \\
\hline Piemonte da Diamantina & 1,64 & 5,52 & 9,40 \\
\hline Médio Sudoeste da Bahia & 1,57 & 5,44 & 9,31 \\
\hline Irecê & 0,86 & 4,62 & 8,38 \\
\hline Velho Chico & 0,81 & 4,58 & 8,35 \\
\hline Chapada Diamantina & 0,83 & 4,46 & 8,09 \\
\hline Piemonte do Paraguaçu & 1,51 & 4,70 & 7,88 \\
\hline Bacia do Paramirim & 0,60 & 4,20 & 7,81 \\
\hline Sisal & 0,88 & 4,21 & 7,53 \\
\hline Bacia do Rio Corrente & 0,59 & 4,00 & 7,41 \\
\hline Vale do Jiquiriçá & 0,97 & 4,09 & 7,20 \\
\hline Semiárido Nordeste II & 0,53 & 3,62 & 6,70 \\
\hline Bacia do Jacuípe & 0,71 & 3,40 & 6,10 \\
\hline
\end{tabular}

Fonte: Censo Demográfico IBGE 2000, 2010 e projeção para 2020 minerados pelo Observatório da Inclusão e Diversidade na Educação - DIVERSIFICA/UFRB.

Na Figura 4 é possível visualizar a evolução do acesso ao ensino superior nos municípios do estado da Bahia. Verificou-se o baixo acesso ao ES na grande maioria dos municípios no ano de 2000, nos anos seguintes ocorreu uma evolução com a ampliação do acesso no ano de 2010, quando se verificou que 213 municípios apresentaram um percentual de 3 a 5\% e 101 municípios de 5 a 10\%. A projeção, também, apontou para um aumento geral no acesso, contudo pode-se perceber que os municípios localizados na região central e mais ao norte do estado apresentaram os menores percentuais de acesso.

Os dados apresentados até aqui indicaram uma ampliação desigual do acesso ao ES nos territórios de identidade da Bahia. Para melhor caracterizar esse processo, a seguir será apresentado o perfil da rede de IES no estado. 
Figura 4. Mapa com a evolução do acesso ao ensino superior em município do estado da Bahia nos anos 2000, 2010 e projeção para 2020.
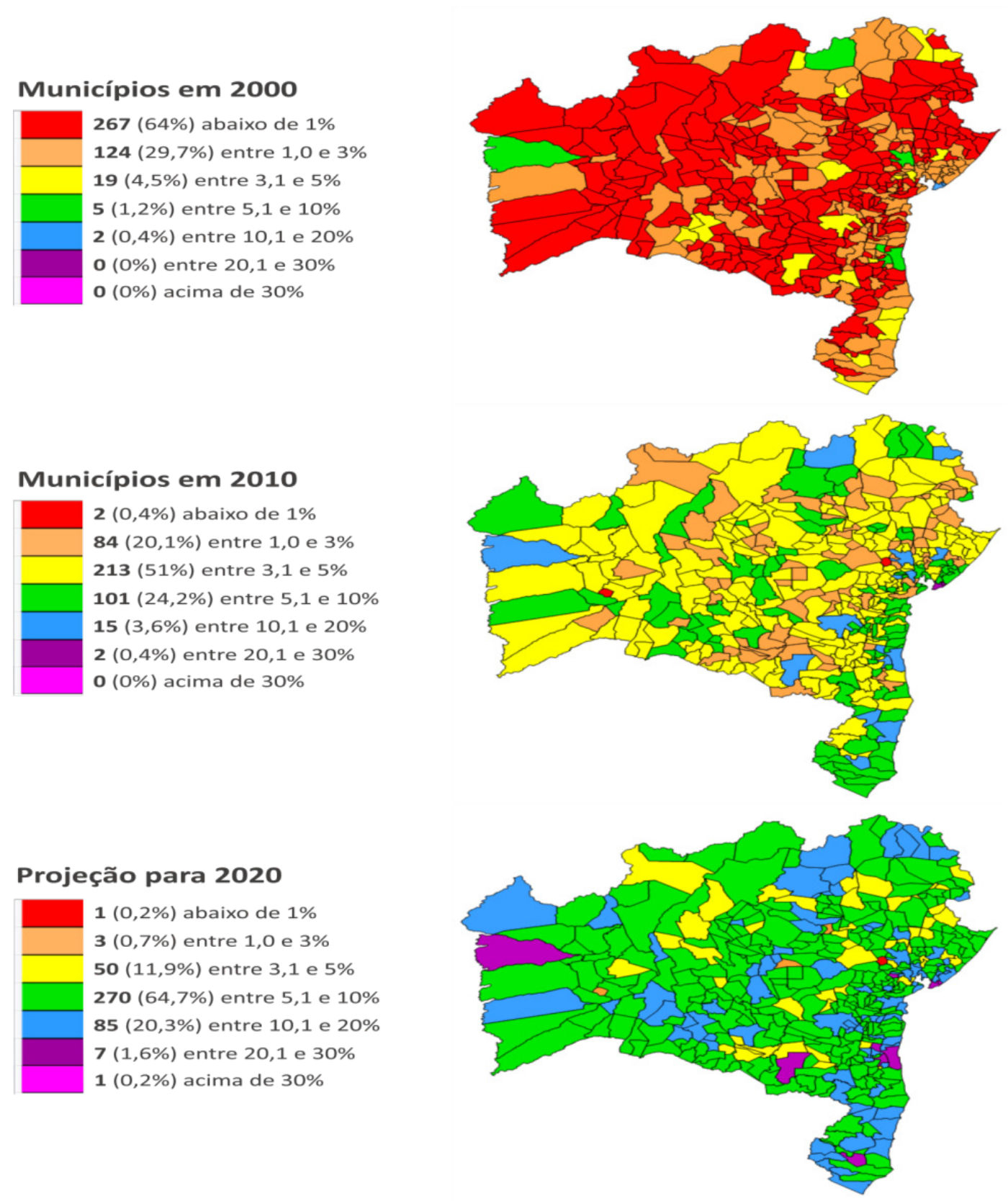

Fonte: Censo Demográfico IBGE 2000, 2010 e projeção para 2020 minerados pelo Observatório da Inclusão e Diversidade na Educação - DIVERSIFICA/UFRB.

\section{Perfil da rede de Instituições de Ensino Superior (IES) na Bahia}

A partir dos dados de registro das IES no Ministério da Educação, por meio do sistema e-MEC, observou-se que estavam inscritas e ativas no sistema 172 IES no estado da Bahia, sendo $49(28,5 \%)$ com sede na capital e $123(71,5 \%)$ no interior. Do total de IES 84,3\% ofereciam cursos no modelo presencial e $15,7 \%$ ofertam cursos presenciais e a distância. 
Estas IES eram, em sua maioria, Faculdades $(n=142 ; 82,6 \%)$. Na sequência, figuram: Centros Universitários ( $\mathrm{n}=18 ; 10,5 \%)$; Universidades $(\mathrm{n}=10 ; 5,8 \%)$ e Institutos Federais de Educação, Ciência e Tecnologia $(n=2 ; 1,2 \%)$. Observou-se então um pequeno número IES organizadas no formato de universidades.

No que tange à categoria administrativa e localização, a maioria das instituições possuía gestão privada $(\mathrm{n}=162 ; 94,2 \%)$, tanto na capital como no interior. A rede pública contava com apenas dez $(n=10)$ IES registradas no estado, sendo oito (8) Universidades (quatro estaduais e quatro federais) e dois (2) Institutos Federais. Esta tendência de predomínio de IES privadas é uma característica do subsistema de educação superior do país, conforme já foi discutido anteriormente.

A Tabela 03 apresenta informações sobre o período de criação destas IES, distribuídas por territórios de identidade e por período de fundação. Conforme ilustra a Tabela 03, o território de identidade RMS concentrou o maior percentual de sedes de IES $(n=60 ; 34,9 \%)$. Outros territórios que se destacaram por possui sede de IES foram: Portal do Sertão $(\mathrm{n}=14 ; 8,1 \%)$; Litoral Sul $(\mathrm{n}=$ 10; 5,8\%); Bacia do Rio Grande $(\mathrm{n}=9 ; 4,7 \%)$; Recôncavo $(\mathrm{n}=8 ; 4,7 \%)$; Sudoeste baiano $(\mathrm{n}=8$; 4,7\%); Sertão do São Francisco $(\mathrm{n}=7 ; 4,1 \%)$; Sisal $(\mathrm{n}=7 ; 4,1 \%)$; Costa do Descobrimento $(\mathrm{n}=$ 6; 3,5\%); Litoral Norte e Agreste Baiano $(\mathrm{n}=6 ; 3,5 \%)$. Os demais possuíam menos de cinco sedes de instituições, contudo cinco TI do estado, não possuíam sede de IES, foram eles: Médio Sudoeste da Bahia, Chapada Diamantina, Bacia do Paramirim, Bacia do Rio Corrente e Vale do Jiquiriçá.

No período “antes de 1991" só existiam instituições registradas nos seguintes TI: Região Metropolitana de Salvador (RMS), Portal do Sertão, Litoral Sul e Vitoria da Conquista. No período “1992 a 1994" o surgimento de novas instituições foi em menor quantidade e se restringiu a RMS e ao TI Bacia do Rio Grande.

A partir de 1995 e até 2003, registrou-se o surgimento intenso de instituições no território de identidade RMS e, também, se iniciou o processo de implantação de novas IES no interior do estado (BOAVENTURA et al, 2015; MOTA JUNIOR E TORRES, 2017). Este processo intensificou-se e ampliou-se no período ente 2004-2010 e manteve-se até o período mais recente (2017-2020). O crescimento expressivo no número de instituições a partir de 1995 se deu pela ampliação de instituições privadas, este processo foi impulsionado por marcos regulatórios que estimulavam o crescimento do setor, sendo assim a expansão se deu tanto na capital do estado como no interior. Destaca-se que no último período ocorreu a criação de 47 novas IES, em praticamente todos os TI e administradas pelo setor privado (Tabela 03). 
Tabela 3. Número de IES do estado da Bahia distribuídas por Território de Identidade de localização da sede e por ano de criação, 2020.

\begin{tabular}{|c|c|c|c|c|c|c|c|}
\hline \multirow[b]{2}{*}{ Território de identidade } & \multicolumn{7}{|c|}{ Período de criação da IES } \\
\hline & $\begin{array}{l}\text { antes } \\
1991 \\
\end{array}$ & $\begin{array}{c}1992 \mathrm{a} \\
1994\end{array}$ & $\begin{array}{c}1995 \mathrm{a} \\
2003\end{array}$ & $\begin{array}{c}2004 \mathrm{a} \\
2011\end{array}$ & $\begin{array}{c}2012 \mathrm{a} \\
2016\end{array}$ & $\begin{array}{c}2017 \mathrm{a} \\
2020\end{array}$ & Total \\
\hline Região Metropolitana de Salvador & 10 & 3 & 22 & 15 & 3 & 7 & 60 \\
\hline Portal do Sertão & 1 & 0 & 5 & 1 & 5 & 2 & 14 \\
\hline Litoral Sul & 1 & 0 & 1 & 3 & 1 & 4 & 10 \\
\hline Bacia do Rio Grande & 0 & 1 & 1 & 4 & 2 & 1 & 9 \\
\hline Recôncavo & 0 & 0 & 1 & 3 & 1 & 3 & 8 \\
\hline Sudoeste baiano & 1 & 0 & 3 & 0 & 2 & 2 & 8 \\
\hline Sertão do São Francisco & 0 & 0 & 0 & 1 & 1 & 5 & 7 \\
\hline Sisal & 0 & 0 & 1 & 1 & 2 & 3 & 7 \\
\hline Costa do Descobrimento & 0 & 0 & 2 & 0 & 1 & 3 & 6 \\
\hline Litoral Norte e Agreste Baiano & 0 & 0 & 1 & 2 & 1 & 2 & 6 \\
\hline Semiárido Nordeste II & 0 & 0 & 1 & 1 & 3 & 0 & 5 \\
\hline Sertão Produtivo & 0 & 0 & 1 & 0 & 0 & 4 & 5 \\
\hline Bacia do Jacuipe & 0 & 0 & 1 & 2 & 0 & 1 & 4 \\
\hline Médio Rio de Contas & 0 & 0 & 1 & 2 & 0 & 1 & 4 \\
\hline Piemonte da Diamantina & 0 & 0 & 0 & 0 & 2 & 2 & 4 \\
\hline Baixo Sul & 0 & 0 & 1 & 0 & 1 & 1 & 3 \\
\hline Extremo Sul & 0 & 0 & 2 & 1 & 0 & 0 & 3 \\
\hline Piemonte Norte do Itapicuru & 0 & 0 & 0 & 1 & 0 & 2 & 3 \\
\hline Irecê & 0 & 0 & 0 & 0 & 0 & 2 & 2 \\
\hline Velho Chico & 0 & 0 & 0 & 0 & 0 & 2 & 2 \\
\hline Itaparica & 0 & 0 & 1 & 0 & 0 & 0 & 1 \\
\hline Piemonte do Paraguaçu & 0 & 0 & 0 & 0 & 1 & 0 & 1 \\
\hline Total & 13 & 4 & 45 & 37 & 26 & 47 & 172 \\
\hline
\end{tabular}

Fonte: Dados minerados do Sistema e-Mec (https://emec.mec.gov.br/) pelo Observatório da Inclusão e Diversi dade na Educação - DIVERSIFICA/UFRB. 
A distribuição de IES nos TI do estado da Bahia foi influenciada pelo nível de desenvolvimento regional e/ou local já consolidado historicamente, a exemplo do grande número de instituições instaladas no território de identidade RMS e em outros territórios de destaque como Portal do Sertão, Litoral Sul, Bacia do Rio Grande e Sudoeste da Bahia. Mais recentemente, verificou-se o crescimento de IES em territórios de identidade que se apresentam como vetores de desenvolvimento no estado como o Sertão do São Francisco e Sertão Produtivo (Tabela 03). Nestes dois TI o incremento no número de instituições no período entre 2017 a 2020, só não foi maior ao registrado para RMS.

A Tabela 04 sintetiza o número de IES por territórios e, também, contabiliza o número de campus das IES nos diversos territórios de identidade do estado. Verifica-se que no estado encontram-se registradas no e-Mec 172 instituições, contando somente com a sede das mesmas, todavia, se forem contabilizados os campi das instituições organizadas no modelo de multicampia, somam-se 83 unidades que ofertam ensino superior. Nesta configuração, considerando a sede das instituições e seus campi percebeu-se que houve uma ampliação da formação superior para todos os TI do estado da Bahia.

Ainda na Tabela 04 é possível observar dados, agregados ao número de IES, que dizem respeito ao acesso ao ES nos diferentes TI da Bahia. Uma análise apurada destas informações agregadas revelou que o número de IES no território foi diretamente proporcional ao maior acesso ao ES, com exceção para os TI de Itaparica e Extremo Sul, os quais possuem baixo número de IES, mas percentual de acesso ao ES superior a média do estado da Bahia. Destaca-se que estes dois territórios estão localizados em zona de fronteira ao norte e ao sul do estado, deste modo, esta localização pode interferir neste percentual de acesso ao ES.

Tabela 3. Número de sedes/campi de IES e percentual da população com acesso ao ES, por territórios de identidade do estado da Bahia, 2020.

\begin{tabular}{|l|c|c|c|}
\hline Território de identidade & Sede IES & Campi IES & $\begin{array}{c}\text { \% de acesso } \\
\text { ao ES } \\
\text { (projeção 2020) }\end{array}$ \\
\hline Bacia do Jacuípe & 4 & - & 6,10 \\
\hline Semiárido Nordeste II & 5 & 2 & 6,70 \\
\hline Vale do Jiquiriçá & - & 3 & 7,20 \\
\hline Bacia do Rio Corrente & - & - & 7,41 \\
\hline Sisal & 7 & 3 & 7,53 \\
\hline
\end{tabular}




\begin{tabular}{|l|c|c|c|}
\hline Bacia do Paramirim & - & - & 7,81 \\
\hline Piemonte do Paraguaçu & 1 & 2 & 7,88 \\
\hline Sertão Produtivo & 5 & 5 & 7,88 \\
\hline Chapada Diamantina & - & 3 & 8,09 \\
\hline Velho Chico & 2 & 4 & 8,35 \\
\hline Irecê & 2 & 4 & 8,38 \\
\hline Médio Sudoeste baiano & - & 1 & 9,31 \\
\hline Piemonte da Diamantina & 4 & 1 & 9,40 \\
\hline Litoral Norte e Agreste Baiano & 6 & 3 & 9,73 \\
\hline Piemonte Norte do Itapicuru & 3 & 3 & 10,10 \\
\hline Sertão do São Francisco & 7 & 3 & 10,31 \\
\hline Baixo Sul & 3 & - & 10,39 \\
\hline Recôncavo & 8 & 8 & 12,12 \\
\hline Médio Rio de Contas & 4 & 3 & 12,87 \\
\hline Sudoeste baiano & 8 & 3 & 13,76 \\
\hline Costa do Descobrimento & 6 & 4 & 14,62 \\
\hline Extremo Sul & 3 & 3 & 14,79 \\
\hline Portal do Sertão & 14 & 6 & 15,19 \\
\hline Bacia do Rio Grande & 9 & 3 & 15,22 \\
\hline Itaparica & 1 & 3 & 15,43 \\
\hline Litoral Sul & 60 & 5 & 16,25 \\
\hline Região Metropolitana de Salvador & 172 & 83 & 25,95 \\
\hline Total /Acesso Bahia & & & 15,3 \\
\hline
\end{tabular}

Fonte: Dados minerados do Sistema e-Mec (https://emec.mec.gov.br/) pelo Observatório da Inclusão e Diversi dade na Educação - DIVERSIFICA/UFRB.

\section{Considerações finais}

Este estudo teve como foco analisar e evolução do acesso da população com 18 anos ou mais ao ensino superior na Bahia e em seus territórios de identidade, bem como, caracterizar a rede de instituições de ensino superior instalada no estado. Verificou-se uma ampliação do acesso ao ensino superior em todo o estado, porém as regiões mais desenvolvidas apresentaram maior acesso, ocorreu um crescimento da presença de pessoas autodeclaradas negaras (pretas e pardas) e de baixa renda no ES, contudo este crescimento não foi suficiente para atingir os níveis de representatividade destes grupos na sociedade baiana. 
No ano 2000 o acesso ao ensino superior dava-se em maior proporção para pessoas residentes em territórios de identidade que concentram a capital do estado e cidades de grande porte que sediavam a rede estadual de Universidades. Deste modo, pode-se afirmar que naquele ano o acesso ao ensino superior no estado era maior para as pessoas residentes em espaços geográficos mais desenvolvidos do ponto de vista econômico. A partir de 2010 e considerando a projeção para 2020, ocorreu uma mudança importante, com o crescimento do acesso ao ES em todos os territórios de identidade, especialmente, aqueles que possuíam menores percentuais no ano 2000. Afirma-se que a rede de instituições que proporcionou esta expansão, no acesso da população baiana com dezoito anos ou mais ao ES, foi, basicamente, formada por instituições privadas, visto que estas foram instaladas, massivamente, na capital e no interior a partir dos anos 90, com crescimento marcante, desde então, até o último período analisado (2017-2020).

Esta rede de IES formada por faculdades com fins lucrativos, geralmente, oferecem currículos mais enxutos e investem, principalmente, em cursos voltados para o mercado de trabalho (SAMPAIO, 2011). Na rede pública foram registradas 10 universidades, destaca-se que estes espaços de formação são responsáveis pela maior parte das pesquisas, bem como, realizam extensão que permitem desenvolvimento de ações em e com comunidades e, portanto, agregam maiores possibilidades de desenvolver novas sociabilidades, convivendo, rompendo e dialogando com as antigas.

Logo, a ampliação do acesso ao ES no estado observada a partir dos dados analisados, neste estudo, por um lado encara-se de com positiva, visto que a formação superior promove a ampliação e fortalecimento do mercado de trabalho nos municípios do interior, com possibilidade de fixação de mão de obra e redução do fluxo migratório capital-interior. Ademais, também pode contribuir com a dinamização da economia local e expansão do mercado consumidor do interior, além, do efeito do gasto dos salários de professores, funcionários. Neste contexto, destaca-se a relação direta, identificada neste estudo, entre o número de IES instaladas no TI e a ampliação do acesso ao ES no mesmo. Por outro lado, uma questão que pode surgir refere-se a características dos cursos ofertados na rede de IES privadas, estes têm sido capazes de formar profissionais qualificados e de atender às demandas sociais existentes?

A rede de universidades públicas do estado apesar do crescimento, ainda, apresentou-se pequena. Sendo assim, pode-se dizer que o potencial destas instituições em contribuírem com o desenvolvimento regional, por meio de pesquisas, da proposição de novas tecnologias e pela relação com a sociedade no fomento de ações de extensão, não foi uma realidade para todo o 
estado. A presença destas instituições foi menor nos TI com menor desenvolvimento econômico, social e, também, com menor acesso ao ensino superior.

Os dados aqui analisados sugerem que a distribuição das IES no estado da Bahia não obedeceu a critérios democráticos e equânimes de ampliação de acesso ao ES para a população do estado. Contraditoriamente, o que se percebeu foi que houve uma concentração de aparatos técnicos em uns lugares em detrimento de outros, o que pode ter ocorrido em função de forças econômicas e políticas que muitas vezes são mútuas.

Com este estudo pretendeu-se contribuir com a discussão sobre desenvolvimento do estado da Bahia, tendo como premissa que a educação superior tem o potencial de articular-se com outros setores, configurando-se como um importante vetor de desenvolvimento. Em função disso, considera-se importante a regulação do Estado no processo de implantação de novas IES, não só pensando na localização destas, mas também, nos cursos ofertados e sua relação com o contexto territorial, em políticas que promovam acesso dos grupos excluídos (regiões menos desenvolvidas, grupos étnico-raciais, pessoas com deficiências e altas habilidades e população de baixa renda), nos currículos que considerem a sociedade multirracial, multiétnica e diversa em povos, comunidades e segmentos variados de classe.

\section{Referências}

AGUIAR, Vilma. Um balanço das políticas do governo Lula para a educação superior: continuidade e ruptura. Rev. Sociol. Polit., Curitiba, v. 24, n. 57, p. 113-126, Mar. 2016 http:// dx.doi.org/10.1590/1678-987316245708.

ALMEIDA FILHO, Naomar M de. O Contexto histórico do bacharelado Interdisciplinar em Saúde no Brasil. In: SANTANA, Luciana Alaíde Alves, OLIVEIRA, Roberval Passos, MEIRELES, Everson, et al. BIS: Bacharelado Interdisciplinar em Saúde - Inovações Curriculares, Formação Interprofissional Integrada e em Ciclos. Universidade Federal do Recôncavo da Bahia - UFRB: Cruz das Almas. 2016. 13-16 p.

ANDRIOLA, Wagner Bandeira; SULIANO, Daniele Cirilo. Avaliação dos impactos sociais oriundos da interiorização da Universidade Federal do Ceará (UFC). Rev. Bras. Estud.

Pedagog., Brasília, v. 96, n. 243, p. 282-298, ago. 2015. Disponível em: < $\underline{\text { http://dx.doi. }}$ org/10.1590/S1414-40772009000200007>.

BAHIA. Decreto 10359 de 23 de maio de 2007. Aprova o Regimento da Secretaria do Planejamento. Disponível em: <https://governo-ba.jusbrasil.com.br/legislacao/75653/decreto-10359-07>. Acesso 29/06/2021

BERTOLIN, Júlio C. G.. Avaliação da educação superior brasileira: relevância, diversidade, equidade e eficácia dos sistemas em tempos de mercantilização. Avaliação (Campinas), Sorocaba, v. 14, n.2, p.351-383, 2009. Disponível em: <http://www.scielo.br/scielo. php?script=sci_arttext\&pid=S1414-40772009000200007\&lng=pt\&nrm=iso $>$. Acessos: 26/11/2020. 
BOAVENTURA, Edivaldo M. et al. Interiorização da Educação Superior no Estado da Bahia. Revista de Desenvolvimento Econômico - RDE: Salvador - Ba - Ano XVII - Edição especial - Dezembro de 2015, p. 653 -67. Disponível em: https://revistas.unifacs.br/index.php/rde/ article/view/4029. Acesso: 26/11/2020

BRASIL. LEI No 9.394 DE 20 de dezembro de 1996. Estabelece as Diretrizes e Bases da Educação Nacional. D.O. DE 23/12/1996, P. 27833. Disponível em: http://www.planalto.gov. br/ccivil_03/leis/19394.htm. Acesso 26/11/2020.

BRASIL. Decreto No 2.306, de 19 de agosto de 1997. Regulamenta, para o Sistema Federal de Ensino. Diário Oficial da União - Seção 1 - 20/8/1997, Página 17991. Disponível em: https://www2.camara.leg.br/legin/fed/decret/1997/decreto-2306-19-agosto-1997-437195-norma-pe.html. Acesso 26/11/2020.

BRASIL. LEI No 11.096 de 13 de janeiro de 2005. Institui o Programa Universidade Para Todos - Prouni, Regula a Atuação de Entidades Beneficentes de Assistência Social no Ensino Superior, Altera a Lei No 10.891, de 9 de Julho de 2004, e dá Outras Providências. D.O.U. DE 14/01/2005, P. 7. Disponível em: http://www.planalto.gov.br/ccivil_03/_ato2004-2006/2005/ lei/111096.htm. Acesso 19/11/2020.

BRASIL. LEI No 12.711 de 29 de agosto de 2012. Dispõe Sobre o Ingresso nas Universidades Federais e nas Instituições Federais de Ensino Técnico de Nível Médio e dá Outras Providências. D.O.U. DE 30/08/2012, P. 1. Disponível em: http://www.planalto.gov.br/ccivil_03/_ ato2011-2014/2012/lei/112711.htm. Acesso 26.11.2020.

BRITO, Leonardo Chagas de. A importância dos estudos sobre interiorização da universidade e reestruturação territorial. Espaço e Economia [Online], 4: 2014. Disponível em:: http:// journals.openedition.org/espacoeconomia/802. Acesso: 12/11/2020

CORBUCCI, PAULO R. Financiamento e Democratização do Acesso à Educação Superior no Brasil: da deserção do Estado ao projeto de reforma. Educ. Soc., Campinas, vol. 25, n. 88, p. 677-701, 2004. Disponível em: https://www.scielo.br/j/es/a/H6DGXS548SGQppcXMx Dnzpn/?lang=pt\&format=pdf. Acesso: 26/11/2020.

CUNHA, LUIZ A. O Ensino Superior no Octênio FHC. Educ. Soc., Campinas, vol. 24, n. 82, p. 37-61, 2003. Disponível em: https:/www.scielo.br/j/es/a/kLKQrxCM8hVbjsQ5vs4SY9n/abstract/?lang=pt\#: :text=O\%20artigo $\% 20$ finaliza $\% 20$ com $\% 20$ um,p\%C3\%BAblico\%20e\%20o\%20setor\%20privado. Acesso 19.11.2020.

INEP - Instituto Nacional de Estudos e Pesquisas Educacionais Anísio Teixeira. Censo da educação superior: 2010 - Resumo técnico. Brasília: Instituto Nacional de Estudos e Pesquisas Educacionais Anísio Teixeira, 2012. Disponível em: https://download.inep.gov.br/ download/superior/censo/2010/resumo_tecnico_censo_educacao_superior_2010.pdf. Acesso: 19.11.2020.

INEP - Instituto Nacional de Estudos e Pesquisas Educacionais Anísio Teixeira. Resumo técnico do Censo da Educação Superior 2018 [recurso eletrônico]. Brasília : Instituto Nacional de Estudos e Pesquisas Educacionais Anísio Teixeira, 2019. Disponível em: http:// download.inep.gov.br/educacao_superior/censo_superior/documentos/2019/censo_da_educacao_superior_2018-notas_estatisticas.pdf. Acesso 26/11/2020 
LOPES, Ronaldo André, SILVA, Guilherme Henrique Gomes da, FERREIRA. Eric Batista - A Lei de Cotas e o acesso à Universidade Federal de Alfenas por estudantes pertencentes a grupos sub-representados. Rev. bras. Estud. pedagog., Brasília, v. 102, n. 260, p. 148-176, jan./abr. 20. https://doi.org/10.24109/2176-6681.rbep.102.i260.3961

BRASIL - Decreto $n^{0} 6.096$, de 24 de abril de 2007. Institui o programa de apoio a Planos de Reestruturação e Expansão das Universidades Federais - REUNI. D.O.U. DE 25/04/2007, P. 7. Disponível em: http://www.planalto.gov.br/ccivil_03/_Ato2007-2010/2007/ Decreto/D6096.htm. Acesso: 26/11/2020.

MEC/INEP/DEAES - Ministério da Educação/Instituto Nacional de Estudos e Pesquisas Educacionais Anísio Teixeira /Diretoria de Estatísticas e Avaliação da Educação Superior. Censo da educação superior sinopse estatística 2004. Brasília - DF, 2005. Disponível em: http:// portal.inep.gov.br/informacao-da-publicacao/-/asset_publisher/6JYIsGMAMkW1/document/ id/489202. Acesso 19.11.2020.

MORHY, Lauro. Universidade no Mundo: universidade em questão. Brasília: Editora Universidade de Brasília, Volume II, 2004.

MOTA JUNIOR, Antônio de Macedo , TORRES, Henderson Carvalho. Educação Superior no Estado da Bahia: contexto histórico e expansão da oferta. Revista Multidisciplinar Plurais: Salvador, v. 2, n.2, p. 83-106,abr./ago. 2017. Disponível em: https://www.revistas.uneb.br/ index.php/plurais/article/view/3955. Acesso 26/11/2020.

OLIVEIRA, Livio Luiz Soares de. A interiorização do ensino superior no Rio Grande do Sul. Revista Indicadores Econômicos, Vol. 44, No. 3 (July 2017): pp. 81-95. Disponível em: https://revistas.dee.spgg.rs.gov.br/index.php/indicadores/article/view/3848. Acesso: 17.11.20.

OLIVEIRA, Anandra Santos Ribeiro de; SILVA, Ivair Ramos. Políticas de Inclusão Social no Ensino Superior Brasileiro: Um Estudo Sobre o Perfil Socioeconômico de Estudantes nos Anos 2010 a 2012. Educ. rev., Belo Horizonte, v. 33, e153900, 2017. Disponível em: $<$ https://doi.org/10.1590/0102-4698153900>.

RODRIGUEZ, Margarita V, MARTINS, Liliana G de A. As Políticas de Privatização e Interiorização do Ensino Superior: Massificação ou Democratização da Educação Brasileira? Revista de Educação, v. 8 n. 8, 2005. Disponível em: https://revista.pgsskroton.com/index. php/educ/article/view/2210. Acesso 25/11/2020.

SAMPAIO, Helena. O setor privado de ensino superior no Brasil: continuidades e transformações. Revista Ensino Superior UNICAMP: Educação e Lucro. Disponível em $<$ https:// www.revistaensinosuperior.gr.unicamp.br/artigos/o-setor-privado-de-ensino-superior-no-brasil-continuidades-e-transformacoes $\geq$. Acesso: 28/06/2021.

SANTANA, Luciana Alaíde A, MEIRELES, Everson, CARVALHO, José Jorge de. Acesso às Instituições Federais de Ensino Superior Brasileiras Após a Lei De Cotas. Revista da FAEEBA - Educação e Contemporaneidade; Salvador - Ba: v. 28 n. 55, 2019. P.127-141. doi: http://dx.doi.org/10.21879/faeeba2358-0194.2019.v28.n55.p127-14. Acesso: 28/06/2021. 
SANTANA, Luciana Alaíde A., MEIRELES, Everson., CARVALHO, José Jorge., NACIF, Paulo Gabriel Soledade. A lei de cotas nas IFES: nenhum retrocesso, nenhum/a negro/a e indígena a menos. Revista da Associação Brasileira de Pesquisadores/as Negros/as (ABPN), [S.1.], v. 13, n. 36, p. 416-439, maio 2021. ISSN 2177-2770. Disponível em: < $\underline{\text { https://abpnre- }}$ vista.org.br/index.php/site/article/view/1256>. Acesso em: 29 jun. 2021.

SANTOS, Pablo Henrique Lacerda dos. A Expansão e Interiorização do Ensino Superior na Bahia: O caso da UFOB. In: XVI Congresso Internacional -FoMerco. Salvador, 2017. Disponível em: http://www.congresso2017.fomerco.com.br/site/ anaiscomplementares2?AREA=10. Acesso: 19.11.2020.

TEIXEIRA, Ana Maria Freitas, LARREA-KILLINGER, Cristina. Expansão e Democratização do Ensino Superior na Bahia: A Implantação da Universidade Federal do Sul Da Bahia e as Expectativas dos Alunos do Ensino Médio Público. Poiésis - Santa Catarina-PR: v. 9, n. 16, 2015. Disponível: <http://dx.doi.org/10.19177/prppge.v9e162015399-417>.

TERRA, Rosane Beatris Mariano da Rocha Barcellos; CARRARO, Guilherme Streit; FERREIRA, Maria Paula da Rosa. As Políticas Públicas de Inclusão ao Ensino Superior: uma análise do contexto brasileiro nos últimos 20 anos. Sequência (Florianópolis), Florianópolis , n. 83, p. 142-159, dez. 2019. Disponível em: <https://doi.org/10.5007/2177$-7055.2019 v 41 n 83 p 142>$.

Recebido: 17 de maio de 2021.

Publicado: 14 de julho de 2021. 